\title{
Correction to: Migration and Environmental Change in Morocco
}

\author{
Correction to: \\ L. Van Praag et al., Migration and Environmental Change \\ in Morocco, IMISCOE Research Series, \\ https://doi.org/10.1007/978-3-030-61390-7
}

The online version of the book was inadvertently published with Table of Contents which contained errors regarding the authorship, which has now been corrected. 